\title{
ORIGINAL ARTICLE \\ The good, the bad and the ugly of catheterization practices among elite athletes with spinal cord injury: a global perspective
}

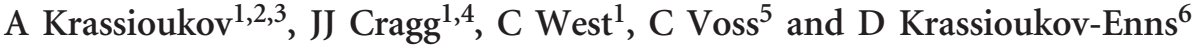

Study design: Despite significant progress in bladder management, urinary tract infections (UTIs) are still common among individuals with spinal cord injury (SCl), and could negatively impact their health and quality of life. However, there are no data available on bladder management and frequency of UTIs among elite athletes with SCl.

Methods: Athletes were assessed during the London 2012 Paralympic Games and 2013 Paracycling World Championships. Athletes completed the standard form of the International Standards to Document remaining Autonomic Functions after SCl, along with the standardized Autonomic Function Questionnaire.

Results: A total of 61 (age $=35.5 \pm 7.7$ years (mean \pm s.d.); time since injury $=16.0 \pm 7.6$ years) elite athletes from 15 countries with traumatic $\mathrm{SCl}$ and who used clean intermittent catheterization were included in this study. The majority (75\%) were from developed nations. Athletes catheterized on average $6 \pm 2$ times per day. We found that individuals who reused catheters experienced more frequent UTIs $(P<0.001)$. We also demonstrated that $83 \%$ of individuals from developed nations never reused a single-use catheter, whereas only $27 \%$ of individuals from developing nations used a new catheter each time $(P<0.001)$. We also noted a twofold increase in the frequency of UTIs in individuals from developing nations $(P=0.027)$.

Conclusions: This study demonstrates that catheter reuse is intimately linked to UTI frequency and provides novel insight on bladder function and management in elite athletes with $\mathrm{SCl}$. Reasons for catheter reuse may be due to a lack of health education and/or a lack of bladder-management resources. (Support: Craig Neilsen Foundation, ICORD, IPC)

Spinal Cord (2015) 53, 78-82; doi:10.1038/sc.2014.208; published online 25 November 2014

\section{INTRODUCTION}

Management of urinary bladder dysfunction is among the highest of priorities for individuals with spinal cord injury (SCI). ${ }^{1}$ Although various options of safe bladder management are presently available for patients who are unable to empty their bladder following SCI, the guidelines of the European Association of Urology recommend anticholenergic drugs and clean intermittent catheterization (CIC) as first-line management. ${ }^{2,3}$ Numerous studies have shown no statistically significant differences in occurrence of urinary tract infections (UTIs) among patients using the sterile technique versus the CIC technique. ${ }^{4-7}$ Interestingly, these studies documented a greater expense associated with the sterile approach, making it the less attractive option in the absence of evidence for superior outcomes. Furthermore, it has also been shown that prolonged indwelling catheterization, whether suprapubic or urethral, may result in higher long-term rates of urological and renal complications than CIC. ${ }^{8,9}$ Based on this evidence, there is general acceptance that CIC is the superior method for preserving bladder compliance and preventing urinary tract complications. ${ }^{10,11}$

During the last decade, numerous versions of catheters for CIC have become available, including self-lubricated, and others that require application of jelly to help minimize urethral trauma and infections. ${ }^{12-14}$ Despite CIC's wide acceptance in clinical practice, clinicians and individuals with SCI are well aware that UTIs and hematuria still occur. Unfortunately, only limited data are available on the association of behavioral and demographic factors, among those who utilize CIC, that predispose individuals to UTIs.

Manufacturer guidelines state that an intermittent catheter is for single-use and it is to be disposed after its use. Unfortunately, owing to the significant costs associated with CIC, individuals will perform multiple catheterizations using the same single-use catheter-a problem that is especially apparent in developing countries. Some studies have suggested that single-use catheters may be reused if cleaned appropriately; however, these authors also cautioned that the reuse of catheters may be associated with increased risk of UTI. ${ }^{15}$ Interestingly, others studies demonstrated that even microwaving of catheters up to $12 \mathrm{~min}$ was not sufficient to eradicate Pseudomonas aeruginosa or Staphylococcus aureus, although there was minimal change to the physical qualities of the catheter. ${ }^{16}$ No studies, however, have attempted to directly examine the relationship between catheter reuse and UTIs, or what factors may influence this relationship. The aim of this study was to examine primary modes for management of

${ }^{1}$ International Collaboration on Repair Discoveries, Vancouver, BC, Canada; ${ }^{2}$ Division of Physical Medicine and Rehabilitation, Department of Medicine, Vancouver, BC, Canada; ${ }^{3}$ GF Strong Rehabilitation Centre, Vancouver Coastal Health, Vancouver, BC, Canada; ${ }^{4}$ School of Population and Public Health, Vancouver, BC, Canada; ${ }^{5}$ Centre for Hip Health and Mobility, University of British Columbia, Vancouver, BC, Canada and ${ }^{6}$ Faculty of Medicine, University of Manitoba, Winnipeg, MB, Canada Correspondence: Professor A Krassioukov, ICORD-BSCC, University of British Columbia, 818 West 10th Avenue, Vancouver, BC, Canada V5Z 1M9. Email: krassioukov@icord.org

Received 11 July 2014; revised 15 September 2014; accepted 13 October 2014; published online 25 November 2014 
the urinary bladder among elite athletes and factors that could contribute to UTIs among athletes who use CIC for bladder management.

\section{MATERIALS AND METHODS}

\section{Participants}

This study was approved by the Ethics Board of the University of British Columbia and the International Paralympic Committee. All participants (volunteer-based sample) provided informed written consent. Assessments were made during the Cardiovascular Health Clinic at the London 2012 Paralympic games and the 2013 Paracycling World Championships, Quebec, Canada. Inclusion criteria for the study were the following: adults with chronic ( $>1$ year post injury) traumatic SCI who use intermittent catheterization for management of their urinary bladder.

First, demographic data (age, sex, representing country), and information relating to SCI (age at injury, cause of injury) as well as sport participation were collected. We divided representing countries into two categories on the basis of economic status according to the World Bank Classification: developing (for example, Brazil, South Africa, Columbia) and developed countries (for example, Canada, US, Italy, Sweden). ${ }^{17}$ Athletes were assessed using standard neurological evaluation according to the International Standards for Neurological Classification of Spinal Cord Injury to determine level and severity of SCI. ${ }^{18}$ Athletes then completed the Autonomic Standards Assessment Form, according to International Standards to Document Remaining Autonomic

\section{Table 1 Participant characteristics}

\begin{tabular}{|c|c|c|}
\hline Variable & Category & n $(\%)$ \\
\hline \multirow[t]{2}{*}{ Sex } & Female & $8(13)$ \\
\hline & Male & $53(87)$ \\
\hline \multirow[t]{3}{*}{ Age category (years) } & $16-30$ & $17(28)$ \\
\hline & $31-45$ & $38(62)$ \\
\hline & $46-60$ & $6(10)$ \\
\hline \multirow[t]{8}{*}{ Time post Injury (years) } & $1-5$ & $4(7)$ \\
\hline & $6-10$ & $13(21)$ \\
\hline & $11-15$ & $12(20)$ \\
\hline & $16-20$ & $15(25)$ \\
\hline & $21-25$ & $8(13)$ \\
\hline & $26-30$ & $5(8)$ \\
\hline & $31-35$ & $2(3)$ \\
\hline & Unknown & $2(3)$ \\
\hline \multirow[t]{4}{*}{ Sport } & Hand-cycling & $20(33)$ \\
\hline & Rugby & $18(30)$ \\
\hline & Basketball & $10(16)$ \\
\hline & Othera & $13(21)$ \\
\hline \multirow[t]{2}{*}{ Country of origin ${ }^{b}$} & Developed & $46(75)$ \\
\hline & Developing & $15(25)$ \\
\hline \multirow[t]{4}{*}{ AIS } & A & 42 (69) \\
\hline & B & $15(25)$ \\
\hline & $\mathrm{C}$ & $1(2)$ \\
\hline & $D$ & $3(5)$ \\
\hline \multirow[t]{3}{*}{ Level of injury } & High tetraplegia (C2-C8) & $28(46)$ \\
\hline & High paraplegia (T2-T6) & $19(31)$ \\
\hline & Low paraplegia (T7-L1) & $14(23)$ \\
\hline \multirow[t]{3}{*}{ Medications } & Baclofen & $11(18)$ \\
\hline & Bladder medications (for example, ditropan) & 24 (39) \\
\hline & $\begin{array}{l}\text { Other (cialis/viagra, antibiotics, nutritional } \\
\text { supplements) }\end{array}$ & $18(30)$ \\
\hline
\end{tabular}

Abbreviations: AIS, American spinal injury association impartment scale. aOther sports included: tennis, table tennis, athletics, swimming, rowing, power lifting, fencing, archery and rowing.

bBased on World Bank Classification. Developed countries included Australia, Canada, Germany, USA and others. Developing countries included Brazil, South Africa, Columbia and others.
Functions after $\mathrm{SCI},{ }^{19}$ in order to assess their general autonomic bladder and bowel control dysfunctions. Specifically, the bladder component of the form contained the following items: (1) awareness of the need to empty bladder and (2) ability to prevent leakage. The frequency of: catheterization, catheter reuse and UTIs during the last year was also assessed.

\section{Data analyses}

Means \pm s.d. or percentages (\%) are reported. Associations between categorical variables were assessed with a $\chi^{2}$-test or the non-parametric alternative (Fisher's exact test) in the case of small cell counts. $t$-tests or Wilcoxon rank-sum tests were used to assess mean differences between groups. Correlations were used to assess relationships between continuous variables. An alpha of 0.05 was used for all analyses.

\section{RESULTS}

\section{Participant characteristics}

A total of 61 Paralympic wheelchair athletes with SCI from 15 countries were assessed (see Table 1). Paralympic athletes from a variety of sports, with a variety of injury severities participated in our study. The majority of athletes $(n=46 ; 75 \%)$ were from developed nations. None of the participants smoked or had a history of cardiopulmonary disease.

\section{Urinary bladder management}

On the basis of the International Standards to Document Remaining Autonomic Functions after SCI autonomic assessment, awareness of the need to empty the urinary bladder was intact (normal function) in only $2 \%$ of athletes, partially preserved in $42 \%$, and totally absent in $56 \%$. The majority of athletes $(87 \%)$ reported either partial or total urinary incontinence. Individuals catheterized on average $6 \pm 2$ times per day (ranging from 1 to 10 per day); the frequency of daily catheterizations was not related to the frequency of UTIs $(P=0.07)$. There were 19 individuals (31\%) who reported reuse of catheters with an average of $34 \pm 50$ times using the same single-use catheter (ranging from 2 to 200 times per catheter).

\section{Frequency of UTIs and catheter reuse}

Individuals who reused catheters reported an average of $4 \pm 3$ UTIs per year. By contrast, individuals who never reused catheters reported an average of $1 \pm 1$ UTI per year. There was a significant association between frequency (number per year) of UTIs and catheter reuse: individuals who reused catheters experienced more frequent UTIs $(P<0.001)$ (Figure 1).

\section{Frequency of UTIs and country of residence}

The majority of individuals (83\%) from developed nations did not reuse catheters (for example, they used a new catheter for each catheterization), while only $27 \%$ of individuals from developing nations used a new catheter each time. There was thus a significant relationship between country status and catheter reuse practices $(P<0.001)$. Correspondingly, among individuals from developed nations, the average frequency of UTIs was $1.6 \pm 2$ per year. By contrast, among athletes from developing nations, the average frequency of UTIs was $3.5 \pm 2.8$ per year. Thus, there was a significantly higher frequency of UTIs among individuals from developing versus developed nations $(P=0.027)$. Namely, individuals from developing nations exhibited two times more UTIs per year on an average compared with individuals from developed nations (Figure 1). 


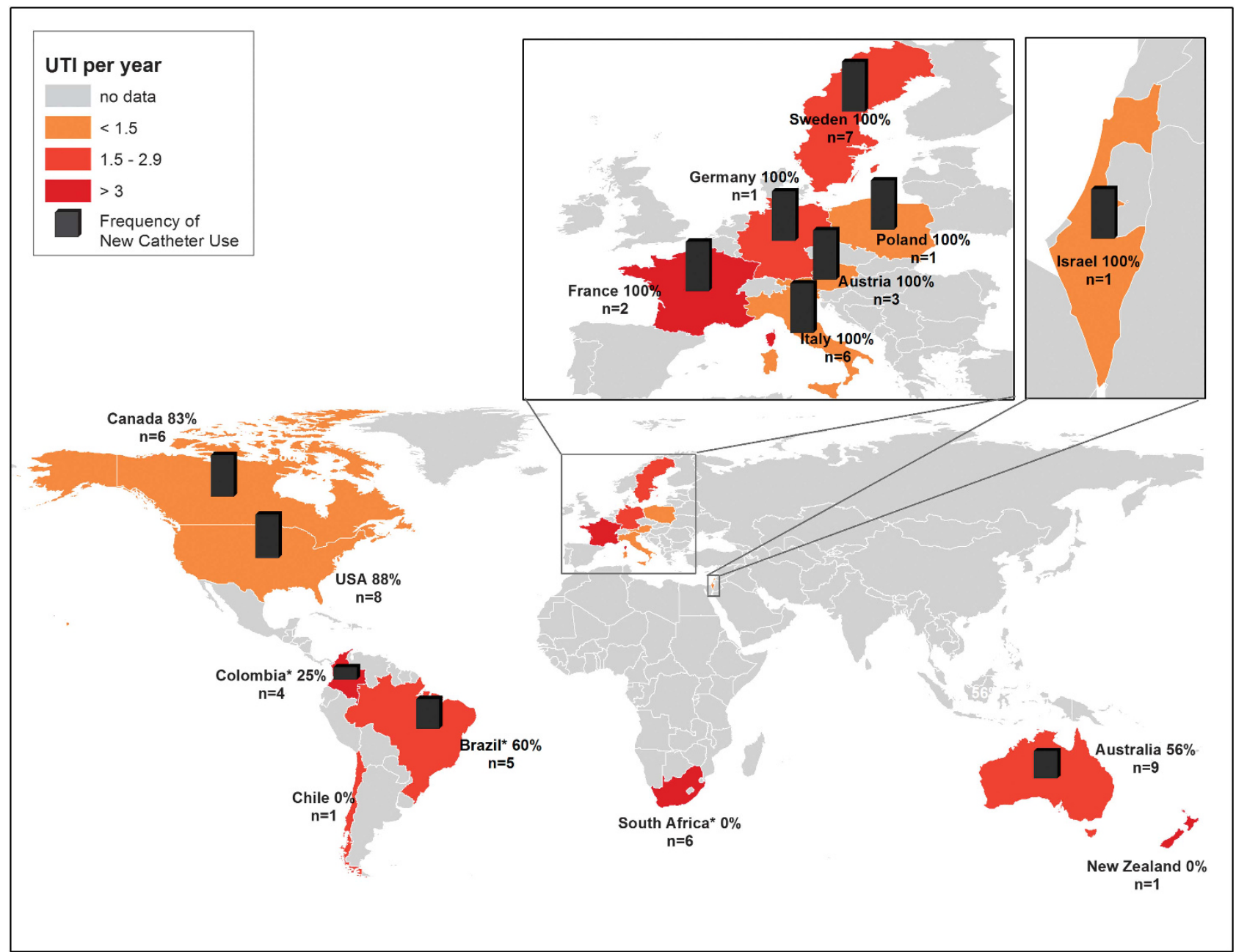

Figure 1 Frequency of urinary tract infections and catheter use worldwide among elite athletes with $\mathrm{SCl}$. Based on 61 athletes from 15 countries assessed during international Paralympic competitions in 2012 and 2013. * denotes developing economy according to World Bank classification.

\section{Frequency of UTI and time post injury}

The average time post injury among athletes in this study was $16.0 \pm 7.6$ years. There was no difference between the time post injury between participants from developed and developing countries (16 years versus 15 years, respectively, $P=0.37$ ). There was also no relationship between time post injury and catheter reuse $(P=0.83)$, nor between time post injury and frequency of UTIs $(P=0.80)$. There was also no relationship between current age and catheter reuse $(P=0.71)$, nor between current age and frequency of UTIs $(P=0.96)$.

\section{DISCUSSION}

In this study, we present novel information on bladder management and frequency of UTIs among elite athletes with SCI. Namely, we found that the frequency of UTIs is intimately linked to catheter reuse, and individuals from developing countries were more likely to reuse catheters and subsequently develop UTIs. Time post injury, age and frequency of catheterization were not associated with frequency of UTIs among elite athletes in this study.

Whereas proper bladder management is an issue for all individuals with SCI, results of the present study indicate that bladder issues are particularly critical to address in developing nations. We demonstrated that the frequency of reuse (up to $83 \%$ ) of intermittent catheters was significantly higher among athletes from the developing world. Consequently, athletes from developing countries reported a higher frequency of UTIs.

One possible explanation for this high frequency of reuse of catheters among athletes is economic issues. Numerous studies have indicated that financial considerations with respect to bladder management are a major concern for health-care providers and individuals with SCI, ${ }^{6,20}$ which may have been the case here. Furthermore, professional development opportunities for health-care providers and caregivers involved in bladder management are limited in the developing world, as is access to up-to-date SCI training resources. This may also be responsible for an inability to provide sufficient education to individuals with SCI with respect to bladder management. ${ }^{21}$ The International SCI community is aware about this gap in knowledge and the need for education opportunities in developing nations. Numerous international organizations, including the ISCoS (International Spinal Cord organisation) and the ASIA (American Spinal Injury Association), are presently championing evidence-based websites with up-to-date educational materials on the management of individuals with SCI and secondary complications. 
Copies of these documents are also quickly becoming available in numerous languages (ISCoS: http:/www.iscos.org.uk/resources/ elearning; ASIA: http://www.asia-spinalinjury.org/elearning/elearning. php).

With respect to other potential factors relating to bladder management in addition to country of origin, sex has been previously documented as a risk factor for development of UTIs following SCI. ${ }^{13,22}$ Unfortunately, we were unable to conduct this evaluation because only a small percent of athletes in our sample (13\%) were females. We also showed that time post injury as well as age did not affect outcomes with respect to UTIs. One may have expected that older athletes, and/or athletes who have more experience with bladder catheterization (greater time since injury), would reuse catheters less and thus develop less frequent UTIs. However, this was not the case in our study. One potential explanation that we ruled out was that there may be a difference in time post injury between participants from developed and developing countries; however, we observed no such difference. Lastly, we were not able to collect information on the methods of cleaning and storage of the reused catheters. However, anecdotally, we observed reused catheters that were either stored in plastic bags or other closed containers, without any cleaning solutions or filled with altogether unknown solutions.

Indeed, there are a variety of catherization practices described in the literature. For example, Vapnek et al. ${ }^{23}$ compared single-use hydrophilic-coated catheters (which reduce friction and urethral trauma) versus controls (standard plastic catheters that were reused up to five times before disposed). Forty-nine patients completed a 12-month study, and the authors supported the use of hydrophilic-coated catheters, as they were associated with less hematuria and a decrease in the rate of UTIs. Interestingly, Kovindha et al. ${ }^{15}$ described the safety of long-term catheter reuse practices among individuals with SCI in Thailand. They reported an average usage time for each silicone catheter as $\sim 3$ years (ranging from 1 to 7 years). ${ }^{15}$ However, the authors also commented that up to $64 \%$ of study participants had presented with foul-smelling urine, and 36\% developed fever and cloudy urine during the last year, thus cautioning that the reuse of catheters may increase the risk of infection.

\section{CONCLUSIONS}

UTIs and bladder dysfunctions have a substantial adverse impact on the health of individuals with SCI. ${ }^{24}$ They prevent individuals from participating in rehabilitation, training and can reduce quality of life. ${ }^{25}$ UTIs can strike at any time with devastating consequences. For example, suffering a UTI at a major international competition may wholly prevent athletes from competing. These infections also pose a significant financial burden on the health-care system-often requiring hospitalization of individuals with SCI. ${ }^{26,27}$ Hence, the ability to reduce UTIs would improve athlete health and allow athletes to train more effectively and for longer periods of time. Our study demonstrates that catheter reuse is intimately linked to UTI frequency and provides novel insight on bladder function and management in elite athletes with SCI. Catheter reuse may be the result of lacking of health education and/or a lack of bladder-management resources. Addressing these issues should be a top priority going forward that will require further research in this area.

\section{DATA ARCHIVING}

There were no data to deposit.

\section{CONFLICT OF INTEREST}

The authors declare no conflict of interest.

\section{ACKNOWLEDGEMENTS}

We would like to thank all Paralympic athletes who took part in this study and the International Paralympic Committee and Paracycling Association for help and logistical support during the study that took place during the London 2012 Paralympics Games and 2013 World Paracycling Championship Quebec, Canada. We also express thanks to Ms S Wong and Ms M Pak for assistance during the study. The Cardiovascular Health Clinic during 2012 Paralympic Games was supported by a Craig H Neilsen Foundation Quality of life grant (PI Dr Krassioukov). Dr C West is funded by a Craig H Neilsen Postdoctoral Fellowship. Research in the laboratory of Dr Krassioukov is supported by grants from Canadian Institutes of Health Research, Heart and Stroke Foundation of BC \& Yukon, Canadian Foundation for Innovation and others. Ms J Cragg is supported by a University of British Columbia Killam Doctoral Award. Dr C Voss is supported by a Heart and Stroke Foundation of Canada and the Michael Smith Foundation for Health Research fellowships.

1 Anderson KD. Targeting recovery: priorities of the spinal cord-injured population. $J$ Neurotrauma 2004; 21: 1371-1383.

2 Lucas MG, Bosch RJ, Burkhard FC, Cruz F, Madden TB, Nambiar AK et al. EAU guidelines on assessment and nonsurgical management of urinary incontinence. Eur Urol 2012; 62: 1130-1142

3 Pannek J, Störhrer M, Blok B, Castro-Diaz D, Del Popolo G, Kramer G et al. Guidelines on Neurogenic Lower Urinary Tract Dysfunction 2013, http://www.uroweb.org/gls/pdf/ 20_Neurogenic\%20LUTD_LR.pdf.

4 Moore KN, Burt J, Voaklander DC. Intermittent catheterization in the rehabilitation setting: a comparison of clean and sterile technique. Clin Rehabil 2006; 20: 461-468.

5 Moore KN, Fader M, Getliffe K. Long-term bladder management by intermittent catheterisation in adults and children. Cochrane database Syst Rev 2007, CD006008.

6 Prieto-Fingerhut T, Banovac K, Lynne CM. A study comparing sterile and nonsterile urethral catheterization in patients with spinal cord injury. Rehabil Nurs 1997; 22: 299-302.

7 Duffy LM, Cleary J, Ahern S, Kuskowski MA, West M, Wheeler L et al. Clean intermittent catheterization: safe, cost-effective bladder management for male residents of $V A$ nursing homes. J Am Geriatr Soc 1995; 43: 865-870.

8 Ord J, Lunn D, Reynard J. Bladder management and risk of bladder stone formation in spinal cord injured patients. J Urol 2003; 170: 1734-1737.

9 Weld KJ, Wall BM, Mangold TA, Steere EL, Dmochowski RR. Influences on renal function in chronic spinal cord injured patients. J Urol 2000; 164: 1490-1493.

10 Wyndaele J-J, Brauner A, Geerlings SE, Bela K, Peter T, Bjerklund-Johanson TE. Clean intermittent catheterization and urinary tract infection: review and guide for future research. BJU Int 2012; 110: E910-E917.

11 Consortium for Spinal Cord Medicine. Bladder management for adults with spinal cord injury: a clinical practice guideline for health-care providers. J Spinal Cord Med 2006; 29: 527-573.

12 Cardenas DD, Moore KN, Dannels-McClure A, Scelza WM, Graves DE, Brooks M et al. Intermittent catheterization with a hydrophilic-coated catheter delays urinary tract infections in acute spinal cord injury: a prospective, randomized, multicenter trial. PM $R$ 2011; 3: 408-417.

13 Cardenas DD, Hoffman JM. Hydrophilic catheters versus noncoated catheters for reducing the incidence of urinary tract infections: a randomized controlled trial. Arch Phys Med Rehabil 2009; 90: 1668-1671.

14 Giannantoni A, Di Stasi SM, Scivoletto G, Virgili G, Dolci S, Porena M et al. Intermittent catheterization with a prelubricated catheter in spinal cord injured patients: a prospective randomized crossover study. J Urol 2001; 166: 130-133.

15 Kovindha A, Mai WNC, Madersbacher H. Reused silicone catheter for clean intermittent catheterization (CIC): is it safe for spinal cord-injured (SCI) men? Spinal Cord 2004; 42: 638-642.

16 Bogaert GA, Goeman L, de Ridder D, Wevers M, Ivens J, Schuermans A et al. The physical and antimicrobial effects of microwave heating and alcohol immersion on catheters that are reused for clean intermittent catheterisation. Eur Urol 2004; 46: 641-646.

17 Ackery A, Tator C, Krassioukov A. A global perspective on spinal cord injury epidemiology. J Neurotrauma 2004; 21: 1355-1370.

18 Kirshblum SC, Waring W, Biering-Sorensen F, Burns SP, Johansen M, Schmidt-Read M et al. Reference for the 2011 revision of the International Standards for Neurological Classification of Spinal Cord Injury. J Spinal Cord Med 2011; 34: 547-554.

19 Krassioukov A, Biering-Sørensen F, Donovan W, Kennelly M, Kirshblum S, Krogh K et al. International standards to document remaining autonomic function after spinal cord injury. J. Spinal Cord Med 2012; 35: 201-210.

20 Wyndaele J, De Ridder D, Everaert K, Heilporn A, Congard-Chassol B. Evaluation of the use of Urocath-Gel catheters for intermittent self-catheterization by male patients using conventional catheters for a long time. Spinal Cord 2000; 38: 97-99.

21 Chhabra HS, Harvey LA, Muldoon S, Chaudhary S, Arora M, Brown DJ et al. www. elearnSCl.org: a global educational initiative of ISCoS. Spinal Cord 2013; 51: 176-182 . 
22 Woodbury MG, Hayes KC, Askes HK. Intermittent catheterization practices following spinal cord injury: a national survey. Can J Urol 2008; 15: 4065-4071.

23 Vapnek JM, Maynard FM, Kim J. A prospective randomized trial of the LoFric hydrophilic coated catheter versus conventional plastic catheter for clean intermittent catheterization. J Urol 2003; 169: 994-998.

24 Craven C, Hitzig SL, Mittmann N. Impact of impairment and secondary health conditions on health preference among Canadians with chronic spinal cord injury. J Spinal Cord Med 2012; 35: 361-370.
25 Tawashy AE, Eng JJ, Krassioukov AV, Miller WC, Sproule S. Aerobic exercise during early rehabilitation for cervical spinal cord injury. Phys Ther 2010; 90: 427-437.

26 Bermingham SL, Hodgkinson S, Wright S, Hayter E, Spinks J, Pellowe C. Intermittent self catheterisation with hydrophilic, gel reservoir, and non-coated catheters: a systematic review and cost effectiveness analysis. BMJ 2013; 346: e8639.

27 Tambyah PA, Knasinski V, Maki DG. The direct costs of nosocomial catheter-associated urinary tract infection in the era of managed care. Infect Control Hosp Epidemiol 2002, 23: 27-31. 